\title{
Exposure to methylphenidate during infancy and adolescence in non-human animals and sensitization to abuse of psychostimulants later in life: a systematic review
}

\author{
Exposição a metilfenidato na infância e adolescência em modelos não humanos \\ e sensibilidade ao abuso de drogas psicoestimulantes na vida adulta: revisão \\ sistemática
}

Juliana Jaboinski, ${ }^{1,2}$ João Carlos Centurion Cabral, ${ }^{1}$ Renan Campos, ${ }^{2,3}$ Daniela Marti Barros ${ }^{2}$

\begin{abstract}
Introduction: Attention deficit hyperactivity disorder (ADHD) is a neuropsychiatric pathology that has an important prevalence among young people and is difficult to diagnose. It is usually treated with methylphenidate, a psychostimulant with a mechanism of action similar to that of cocaine. Previous studies show that repeated use of psychostimulants during childhood or adolescence may sensitize subjects, making them more prone to later abuse of psychostimulant drugs such as cocaine and methamphetamine. Objective: To review experimental studies in non-human models (rodents and monkeys) treated with methylphenidate during infancy or adolescence and tested for reinforcing effects on psychostimulant drugs in adulthood.

Method: Systematic collection of data was performed on four databases (Web of Knowledge, PsycARTICLE, PubMed and SciELO). The initial search identified 202 articles published from 2009 to 2014, which were screened for eligibility. Seven articles met the inclusion criteria and were reviewed in this study.

Results: The findings indicate that early exposure to methylphenidate has an effect on an ADHD animal model, specifically, on spontaneously hypertensive strain rats, especially those tested using the self-administration paradigm.

Conclusion: Future studies should prioritize the spontaneously hypertensive rat strain - an animal model of ADHD. Experimental designs comparing different behavioral paradigms and modes of administration using this strain could lead to improved understanding of the effects of exposure to methylphenidate during childhood and adolescence.

Keywords: Methylphenidate, attention deficit hyperactivity disorder, animal models, analeptic drugs, drug abuse.
\end{abstract}

\section{Resumo}

Introdução: $O$ transtorno de déficit de atenção e hiperatividade (TDAH) é uma patologia neuropsiquiátrica de difícil diagnóstico e de relevante prevalência entre pessoas jovens. É comumente tratada com metilfenidato, uma substância psicoestimulante com mecanismo de ação similar ao da cocaína. Estudos prévios demonstram que o uso contínuo de fármacos estimulantes na infância ou adolescência pode sensibilizar o sujeito para o subsequente abuso de drogas psicoestimulantes, como cocaína e metanfetamina.

Objetivo: Revisar estudos experimentais em modelos não humanos (roedores e macacos) tratados com metilfenidato na infância ou na adolescência e testados para os efeitos reforçadores de drogas psicoestimulantes na vida adulta.

Método: A coleta sistemática dos dados foi realizada em quatro bases de dados (Web of Knowledge, PsycARTICLE, PubMed e SciELO). Na busca inicial, 202 artigos publicados entre 2009 e 2014 foram triados. Destes, sete preencheram os critérios de inclusão e foram revisados neste estudo.

Resultados: Os dados indicam um efeito da pré-exposição ao metilfenidato sobre o TDAH em animais adolescentes da linhagem do rato espontaneamente hipertensivo (spontaneously hypertensive strain, SHR). Esse efeito foi encontrado, sobretudo, nos estudos que utilizaram o paradigma de autoadministração. Conclusão: Estudos futuros devem priorizar a linhagem dos SHR modelo animal do TDAH. Delineamentos que comparem diferentes paradigmas comportamentais e formas de administração utilizando essa linhagem podem prover uma melhor compreensão do efeito da exposição ao metilfenidato na infância e adolescência.

Descritores: Metilfenidato, transtorno de déficit de atenção e hiperatividade, modelos animais, drogas analépticas, abuso de drogas.

\footnotetext{
${ }^{1}$ Institute of Psychology, Universidade Federal do Rio Grande do Sul (UFRGS), Porto Alegre, RS, Brazil. ${ }^{2}$ Institute of Biological Sciences, Universidade Federal do Rio Grande (FURG), Rio Grande, RS, Brazil. ${ }^{3}$ Institut de Neurosciences Cognitives et Intégratives d'Aquitaine, Université de Bordeaux, Bordeaux, France. Financial support: none.

Submitted Dec 18 2014, accepted for publication Apr 25 2015. No conflicts of interest declared concerning the publication of this article.

Suggested citation: Jaboinski J, Cabral JC, Campos R, Barros DM. Exposure to methylphenidate during infancy and adolescence in non-human animals and sensitization to abuse of psychostimulants later in life: a systematic review. Trends Psychiatry Psychother. 2015;37(3):107-117. http://dx.doi.org/10.1590/22376089-2014-0060
} 


\section{Introduction}

Stimulant drugs have been used to treat attention deficit hyperactivity disorder (ADHD) for more than 70 years. This disorder is usually diagnosed in children and teenagers and may persist through adulthood. ${ }^{1}$

Relevant concerns have been raised in recent decades regarding the impact of chronic use of psychostimulants such as methylphenidate (MPH) during brain development. One pertinent point raised is the hypothesis that use of MPH during childhood and adolescence may sensitize the developing brain, eliciting susceptibility to drug abuse (especially to psychostimulants) in adulthood. ${ }^{2}$ Considering the widespread use of this drug, studies that aim to investigate its potential impact on the development of the brain are warranted, especially when they concern potential adverse consequences such as drug addiction.

Attention deficit hyperactivity disorder is a neuropsychiatric pathology with an important prevalence among young people and its rate of diagnosis has increased by $41 \%$ over the last 10 years, with a significant increase among male adolescents aged 14 to $17 .{ }^{3}$ Diagnosis of this disorder is based on persistent dysfunctional levels of attention, impulsivity and motor activity (hyperactivity). ${ }^{4}$ To date there are no known biological markers or laboratory tests that can confirm its presence and so the disorder is mainly identified through observation of behavioral features. ${ }^{4}$

According to the fifth edition of the Diagnostic and Statistical Manual of Mental Disorders (DSM-5), ${ }^{5}$ ADHD is characterized by 18 symptoms, nine of which are related to inattention traits, six to hyperactivity traits and three to impulsivity traits. The cutoff for diagnosis is six traits, i.e. the number of symptoms above which the subject is diagnosed with ADHD is six inattention traits and/or six hyperactivity-impulsivity traits. The cutoff for adults is five traits.

The pathophysiology of ADHD is believed to be related to an abnormality within the catecholaminergic signaling system involving release of dopamine (DA) in areas such as the frontal lobe and those involving the limbic system. ${ }^{6}$ One theory postulated to explain the etiology of $A D H D$ is a fronto-striatal dopaminergic hypofunction.

Because the frontal lobe, mainly the prefrontal cortex, is responsible for attentional and regulatory processes (inhibitory control, impulsivity), and the nigrostriatal pathway is responsible for motor activities (hyperactivity), the clinical features of ADHD correlate to the areas involved. However, the neurobiology of this disorder is likely to involve more than dopaminergic hypofunction, since not all patients respond well to the standard medication, $\mathrm{MPH}$, and not all psychostimulants appear to be effective for treatment. ${ }^{6,7}$
The pharmacological action of MPH is ascribed to blockage of dopamine (DA) and noradrenaline (NA) reuptake within the prefrontal cortex, thereby increasing the levels of both neurotransmitters in this region and enhancing the functions for which they are responsible (attention, inhibitory control and working memory). ${ }^{1}$ Interestingly, cocaine also causes increased availability of DA, in particular in the dopaminergic mesolimbic pathway, which is known as the reward pathway in the brain. A large body of evidence suggests that this action within the reward circuitry underlies the addictive properties of cocaine. ${ }^{6,8-10}$ Thus, both ADHD patients and people addicted to cocaine are likely to have a common neuronal need for dopaminergic stimulation. Nonetheless, the direction of this relationship in terms of whether MPH sensitizes the subject's brain for subsequent use of psychostimulants or constitutes a protective tool remains a mystery.

On one hand, some studies have assessed utilization of $\mathrm{MPH}$ as a pharmacological tool for treatment of cocaine ${ }^{11,12}$ and methamphetamine (MET) ${ }^{13}$ addictions and there seems to be a consensus in the literature that $\mathrm{MPH}$ is not a viable method for this purpose. On the other hand, other studies have been conducted to evaluate the capacity of MPH to elicit subsequent drug abuse. In one study, Kollins et al. ${ }^{14}$ reviewed 60 studies of humans with and without ADHD diagnoses and of several animal models (e.g., rat, baboon, monkey, dog and squirrel). The aim of that study was to evaluate the pharmacological and behavioral profiles of $\mathrm{MPH}$, discussing implications for its potential abuse, while making a comparison with other psychostimulants such as cocaine and D-amphetamine. Of the 60 studies reviewed, the authors asserted that 48 demonstrated that MPH acted in a similar way to cocaine and D-amphetamine, exhibiting reinforcing effects and similar subjective effects in humans, assessed using selfreport scales. In contrast, Wilens et al. ${ }^{15}$ reviewed six studies using a meta-analysis approach and suggested that treatment with stimulants during adolescence was not associated with an increased predisposition to abuse of a range of types of drug - including alcohol and psychostimulants. Interestingly, that study compiled results that ascribed a protective component to the use of stimulant medication for ADHD. Further blurring the subject, recent work has found no relationship between chronic MPH use during childhood and adolescence and drug abuse in adult life. ${ }^{16}$

Studies using animal models aim to understand the effects of drugs on the physiology of the brain and enable controlled behavioral evaluation and investigation of the biological mechanisms underlying such processes. In the case of drug addiction, several paradigms have been widely used to mimic addiction-related processes in non- 
human animal models. Some of them appear recurrently throughout the studies included in this review and are therefore worth mentioning.

In the conditioned place preference (CPP) paradigm, animals are administered a drug prior to being placed in one environment/context. In another session they are administered with a neutral substance (a vehicle injection) before being placed in an alternative environment. Following several pairing sessions, the animals are allowed to move freely between the two environments, while in a drug-free state, and the amount of time spent in the drug-associated context is taken as an index of preference for the drug. ${ }^{17-19}$ Another recurrent behavioral paradigm is used to assess aversive properties of drugs. The conditioned taste aversion (CTA) task evaluates animals' tendency to reduce consumption of a usually preferred substance (e.g., sucrose, saccharin, water). After several pairings of this substance with a specific drug, a reliable reduction in fluid intake is produced, thus conveying a learned association between the aversive effects of the drug and the taste of the substance. ${ }^{20}$

The self-administration model has been successfully used to measure psychostimulant reinforcement in non-human animal models. ${ }^{21-23}$ In this model, animals are trained to perform an action in order to receive an infusion of a drug. In this kind of experiment, various different manipulations can be performed to examine their effects on self-administration. One useful feature of the self-administration model is its capacity to mimic real-life drug-taking in humans. ${ }^{24}$

Finally, one further recurrent approach is an assessment of locomotor sensitization/crosssensitization, based on a phenomenon by which locomotor activity is enhanced following a drug challenge using a dose to which the animal has repeatedly been exposed previously. In cross-sensitization, animals repeatedly treated with one stimulant display greater locomotor activity when later exposed to another stimulant. ${ }^{25}$ Locomotor sensitization is considered a behavioral model of drug induced neuronal plasticity, ${ }^{26}$ being paralleled by neuroadaptations underlain by changes in molecular signaling cascades. ${ }^{27}$

However, even using this kind of experimental evaluation, studies of $\mathrm{MPH}$ with humans and with nonhuman animal models have reported complex and variable results.

For instance, a study published by Brandon et al. ${ }^{28}$ using adolescent male Sprague-Dawley (SD) rats demonstrated that MPH may have a sensitizing effect towards use of cocaine in adulthood. ${ }^{13}$ Animals exhibited locomotor cross-sensitization when initially exposed to $\mathrm{MPH}$ and afterwards to cocaine. Pretreatment with MPH also increased self-administration of cocaine. ${ }^{28}$ As such, the results suggest that pretreatment with $\mathrm{MPH}$ could increase vulnerability to cocaine abuse later in life, as demonstrated by cross-sensitization between these two stimulants, and may also enhance these animals' vulnerability to the reinforcing effects of cocaine, as observed through increased cocaine self-administration. Another study using a non-human primate model (Rhesus monkeys) was designed to compare the reinforcing properties of Atomoxetine, a non-stimulant medication for ADHD, with the effects of two other drugs, MPH and desipramine. In order to achieve this, the animals were initially sensitized with cocaine and afterwards were given the opportunity to self-administer atomoxetine, desipramine or $\mathrm{MPH}$. The results indicated that $\mathrm{MPH}$, similarly to cocaine and conversely to Atomoxetine and Desipramine, functioned as a positive reinforcer. ${ }^{29}$ These data support previous reports using rodents as models. ${ }^{28}$ On the other hand, a more recent publication demonstrated that repeated treatment with intragastric MPH did not induce behavioral sensitization in adolescent rats. Additionally, cross-sensitization was also not observed when the animals underwent early treatment with $\mathrm{MPH}$ and were later challenged with nicotine during adolescence or adulthood. ${ }^{30}$

Finally, this brief review indicates that some questions regarding the effects of early administration of $\mathrm{MPH}$ still remain to be answered: does early administration induce sensitization or lead to enhanced proneness to later psychostimulant abuse? Approaching this complex subject within a neuropsychopharmacological puzzle, this review aims to cover a modest proportion of this field. Therefore, we performed a systematic review of the effects of exposure to MPH during childhood and adolescence on abuse of psychostimulant drugs later in life. In view of the multiplicity of variables to be analyzed, as well as the difficulty of comparing results obtained from studies with humans, this review focuses on studies that utilized non-human animal models (rodents and monkeys). It is believed that the data they produce allow for a more concise and productive discussion because of the possibility of greater control of variables in such models.

\section{Materials and methods}

Systematic collection of data was performed in June 2014 using the following electronic databases: Web of Knowledge (ISI), PsycARTICLE (APA), PubMed (MEDLINE) and SciELO (Scielo.org). Articles published between 2009 and 2014 were sampled using the following search strategy: (((Methylphenidate [Title]) OR (Ritalin [Title])) AND ((Animal [Title/Abstract]) OR (mice [Title/Abstract]) 
OR (rat [Title/Abstract]) OR (rodent [Title/Abstract]) OR (primate [Title/Abstract])) AND ((Self-administration [Title/Abstract]) OR ("substance dependence" [Title/ Abstract]) OR ("substance use" [Title/Abstract]) OR ("long term effects" [Title/Abstract])) AND ((Drugs [Title/Abstract]) OR (cocaine [Title/Abstract]) OR (nicotine [Title/Abstract]) OR (addiction [Title/Abstract]) OR (abuse [Title/Abstract]))).

The initial searches located a total of 202 publications. These underwent a screening process to assess their adequacy based on inclusion and exclusion criteria and to evaluate the methodology of the studies. This process was carried out by two independent reviewers previously trained for the task. The following items were selected as inclusion criteria: a) aim of the study - articles designed to investigate the long-term effects of methylphenidate on recreational drug use; b) independent variable - articles in which at least one of the independent variables is use of methylphenidate; c) type of publication - articles published in peer-reviewed scientific journals; d) period of publication - articles published from 2009 to 2014; and e) language - articles published in English, Spanish or Portuguese. Articles that were not relevant were then excluded by application of the following criteria: a) dependent variable - studies that did not contain the use of at least one stimulant drug as a dependent variable; b) study design - studies that did not use an experimental design; and c) accessibility - articles that were not available for online access.

At the end of this process, seven articles were selected for review (Figure 1). The rate of agreement between the reviewers was $96.3 \%$. In cases of discrepancies between the two reviewers' evaluations, a third researcher was requested to participate.

The articles reviewed were organized by author, publication year, sample size, animal model (including strain), MPH dose and route of administration, period of development during which the exposure to MPH was carried out, behavioral task and main results (Table 1). It is important to mention that the periods of development that were included in this review were from the beginning of weaning to late adolescence. Weaning is a transition between two modes of feeding, and is a progressive and developmental process unique to mammalian young. Rats mature rapidly during infancy and become sexually mature at about 6 weeks of age. ${ }^{31,32}$ Indeed, the average weaning age for rats is approximately 3 weeks and the late adolescence is approximately up to postnatal day 42 , which is the period considered in this review. Non-human primates have an extended period of adolescence, ${ }^{33}$ so the late adolescence period for primates (rhesus monkeys) was considered as up to 4.5 years. ${ }^{34}$

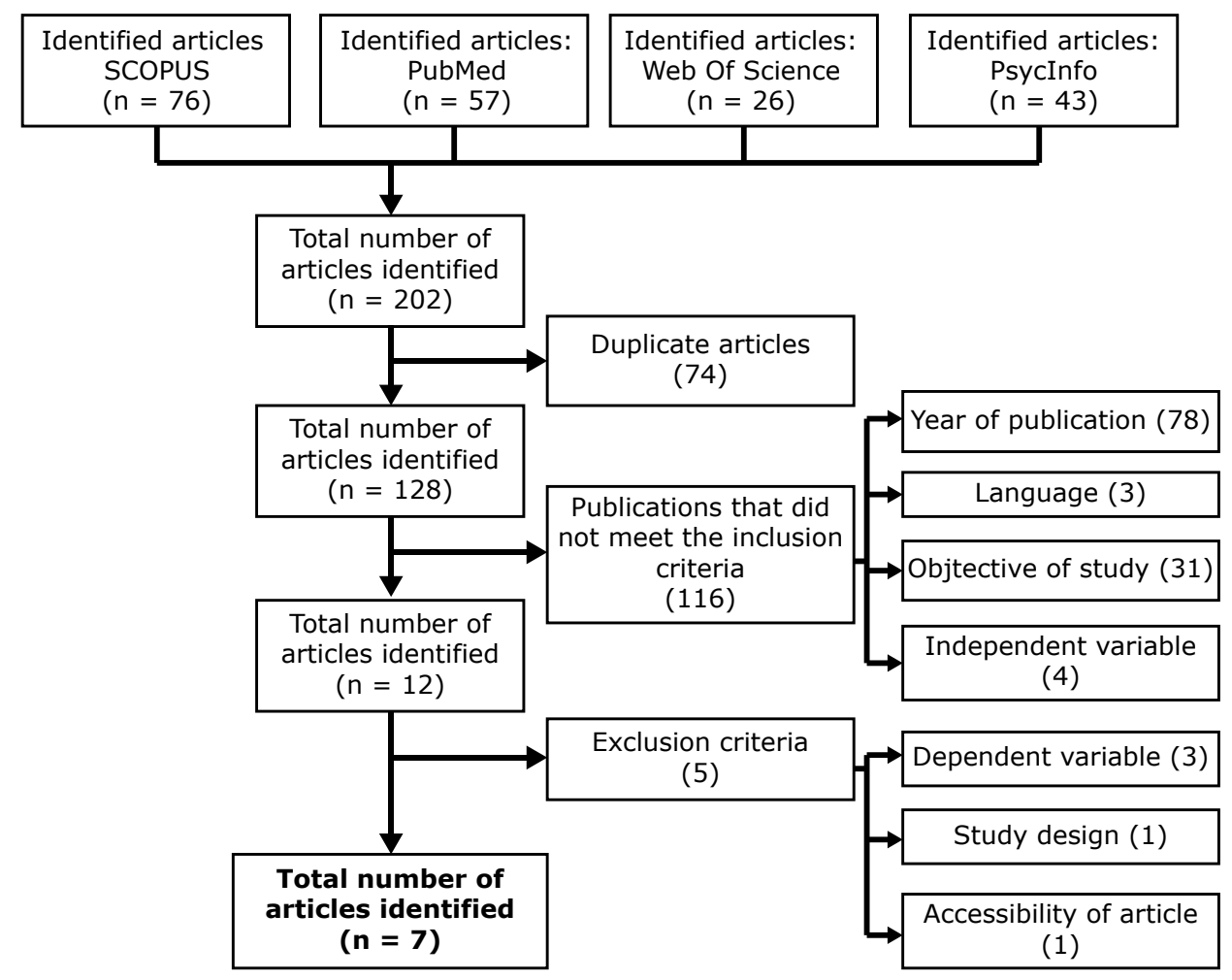

Figure 1 - Article selection process 
Table 1 - Studies of early exposure to methylphenidate and risk of later stimulant drug use in animal models

\begin{tabular}{|c|c|c|c|c|c|c|}
\hline Study & n (CG-EG) & $\begin{array}{l}\text { Animals/ } \\
\text { strains }\end{array}$ & $\begin{array}{c}\text { MPH dose/ } \\
\text { administration } \\
\text { route }\end{array}$ & $\begin{array}{c}\text { Beginning } \\
\text { of exposure: } \\
\text { development } \\
\text { period }\end{array}$ & $\begin{array}{l}\text { Dependent } \\
\text { variables }\end{array}$ & Main results \\
\hline Jordan et al. ${ }^{3}$ & $10-7 / 10-10 / 9-7$ & $\begin{array}{l}\text { SHR vs. WKY } \\
\text { and WIS rats }(ð)\end{array}$ & $\begin{array}{l}\text { Clinical: } 1.5 \mathrm{mg} / \\
\mathrm{kg} / \text { oral route }\end{array}$ & $\begin{array}{l}\text { Adolescence (25 } \\
\text { days) }\end{array}$ & $\begin{array}{l}\text { Cocaine SA }(0.3 \\
\mathrm{mg} / \mathrm{kg})\end{array}$ & $\begin{array}{l}\text { SHR ( } \uparrow \text { Cocaine } \\
\text { SA) } \\
\text { WKY and WIS } \\
\text { (NS) }\end{array}$ \\
\hline Gill et al. ${ }^{35}$ & $8 / 8$ & $\begin{array}{l}\text { Rhesus monkeys } \\
\left(\lambda^{\prime}\right)\end{array}$ & $\begin{array}{l}\text { Clinical: } 20-40 \\
\text { mg/oral route }\end{array}$ & $\begin{array}{l}\text { Adolescence } \\
\text { (40.5-38 months) }\end{array}$ & $\begin{array}{l}\text { Cocaine SA } \\
(0.001 \text { to } 0.1 \\
\mathrm{mg} / \mathrm{kg}) \\
\text { Morphometric } \\
\text { measures } \\
\text { PET imaging: D2/ } \\
\text { D3 receptors and } \\
\text { DAT }\end{array}$ & $\begin{array}{l}\text { D2/D3 receptor } \\
\text { availability (NS) } \\
\text { DAT availability } \\
\text { (NS) } \\
\text { Cocaine SA (NS) }\end{array}$ \\
\hline $\begin{array}{l}\text { Wetzell \& Riley } \\
(\text { Exp. 1 })^{36}\end{array}$ & $42 / 42$ & $\begin{array}{l}\text { Sprague Dawley } \\
\text { rats }\left(\delta^{\lambda}\right)\end{array}$ & $\begin{array}{l}\text { Clinical: } 2 \mathrm{mg} / \mathrm{kg} \\
\text { / Intraperitoneal } \\
\text { route }\end{array}$ & $\begin{array}{l}\text { Adolescence (25 } \\
\text { days) }\end{array}$ & CTA & NS \\
\hline $\begin{array}{l}\text { Wetzell \& Riley } \\
(\text { Exp. 2) })^{36}\end{array}$ & $24 / 24$ & $\begin{array}{l}\text { Sprague Dawley } \\
\text { rats }\left(\delta^{\lambda}\right)\end{array}$ & $\begin{array}{l}\text { Non-clinical: } \\
10 \mathrm{mg} / \mathrm{kg} / \\
\text { Intraperitoneal } \\
\text { route }\end{array}$ & $\begin{array}{l}\text { Adolescence ( } 25 \\
\text { days) }\end{array}$ & CTA & NS \\
\hline Peña et al. ${ }^{37}$ & - & $\begin{array}{l}\text { SHR } \times \text { WIS rats } \\
\left(0^{3}\right)\end{array}$ & $\begin{array}{l}\text { Clinical: } 1.25 \\
\mathrm{mg} / \mathrm{kg} \\
\text { Non-Clinical: } 5 \\
\mathrm{mg} / \mathrm{kg} \\
25 \mathrm{mg} / \mathrm{kg} / \\
\text { intraperitoneal } \\
\text { route }\end{array}$ & $\begin{array}{l}\text { Adolescence ( } 21 \\
\text { days) }\end{array}$ & $\mathrm{CPP}(\mathrm{MPH})$ & $\begin{array}{l}\text { MPH as a } \\
\text { reinforcer: } \\
\text { WIS (significant } \\
\text { when compared } \\
\text { with CG) } \\
\text { SHR (NS when } \\
\text { compared with } \\
\text { CG) }\end{array}$ \\
\hline Harvey et al. ${ }^{21}$ & $\pm 6-8$ per group & $\begin{array}{l}\text { SHR } X \text { WKY and } \\
\text { WIS rats }\left(0^{2}\right)\end{array}$ & $\begin{array}{l}\text { Clinical: } 1.5 \mathrm{mg} / \\
\mathrm{kg} / \text { oral route }\end{array}$ & $\begin{array}{l}\text { Adolescence ( } 25 \\
\text { days) }\end{array}$ & $\begin{array}{l}\text { Cocaine SA } \\
(0.003 \text { to } 1 \mathrm{mg} / \\
\mathrm{kg}) \\
\text { Functioning of } \\
\text { DAT }\end{array}$ & $\begin{array}{l}\text { MPH-treated } \\
\text { SHR exhibited: } \\
\text { faster cocaine SA; } \\
\text { upward shift in } \\
\text { the cocaine dose- } \\
\text { response function; } \\
\downarrow \text { DAT in the PFC }\end{array}$ \\
\hline $\begin{array}{l}\text { Crawford et } \\
\text { al. }{ }^{22}\end{array}$ & $\pm 6-9$ per group & $\begin{array}{l}\text { Sprague Dawley } \\
\text { rats }\left(+/ \delta^{\wedge}\right)\end{array}$ & $\begin{array}{l}\text { Clinical: } 0.2 \mathrm{mg} / \\
\mathrm{kg} \\
\text { Non-Clinical: } \\
5 \mathrm{mg} / \mathrm{kg} / \\
\text { intraperitoneal } \\
\text { route }\end{array}$ & $\begin{array}{l}\text { Childhood (11 } \\
\text { days) }\end{array}$ & $\begin{array}{l}\text { Cocaine SA } \\
(0.25 / 0.75 \mathrm{mg} / \\
\mathrm{kg} / \text { infus. }) \\
\text { CPP }\end{array}$ & $\begin{array}{l}\text { MPH ( } \uparrow \text { Cocaine } \\
\text { SA (d only)) } \\
\text { MPH X CPP (NS) }\end{array}$ \\
\hline Griggs et al. ${ }^{23}$ & 8-10 per group & $\begin{array}{l}\text { Sprague Dawley } \\
\text { rats }\left(\partial^{\lambda}\right)\end{array}$ & $\begin{array}{l}\text { Clinical: } 1.5 \mathrm{mg} / \\
\mathrm{kg} \\
3 \mathrm{mg} / \mathrm{kg} / \\
\text { subcutaneous } \\
\text { route }\end{array}$ & $\begin{array}{l}\text { Adolescence ( } 37 \\
\text { days) }\end{array}$ & $\begin{array}{l}\text { Cocaine SA (1 } \\
\mathrm{mg} / \mathrm{kg} / \text { infus.) }\end{array}$ & $\begin{array}{l}\text { Intermittent MPH } \\
\text { administration: } \\
\text { hyperactivity in } \\
\text { several measures } \\
\text { and } \uparrow \text { sensitivity } \\
\text { to the reinforcing } \\
\text { effects of cocaine; } \\
\text { continuous MPH } \\
\text { administration: } \\
\text { hypoactivity and } \\
\text { cocaine SA (NS) }\end{array}$ \\
\hline
\end{tabular}

$\delta=$ male; $q=$ female $; \uparrow=$ increase $\downarrow=$ decrease; $C G=$ control group; CPP = conditioned place preference; CTA = conditioned taste aversion; DAT = dopamine transporter; $\mathrm{EG}=$ experimental group; Exp. = experiment; infus. = infusion; $\mathrm{MPH}=$ methylphenidate; $\mathrm{NS}=$ not significant; $\mathrm{PFC}=$ prefrontal cortex; $\mathrm{SA}=$ selfadministration; SHR = spontaneously hypertensive rat; WIS = Wistar rat; WKY = Wistar-Kyoto rat.

\section{Results}

In total, seven studies that met all of the inclusion criteria defined for this systematic review were included. Two of these studies did not detect any effect from exposure to MPH during childhood/adolescence on subsequent use of psychostimulants. In contrast, two studies did observe such effects. Finally, the three remaining studies compared different methodological aspects such as animal strains, behavioral tasks or routes of drug administration. 


\section{Studies reporting no effect of early exposure to MPH on adult life}

Wetzell \& Riley ${ }^{36}$ examined the effects of adolescent exposure to MPH on the aversive properties of cocaine in adulthood using the CTA procedure. In order to address this issue, male SD rats were intraperitoneally (ip) administered with either a therapeutic ( $2 \mathrm{mg} / \mathrm{kg}$, two daily sessions) or a high dose (10 mg/kg one daily session) of MPH for 15 consecutive days during adolescence, and then tested in the CTA task with cocaine. It is important to note that the dose of $\mathrm{MPH}$ regarded as therapeutic was based on its equivalence to therapeutic doses used in adolescent humans. ${ }^{38}$ The results showed that early exposure to MPH does not alter the aversive properties of cocaine in adulthood. Thus, the authors argue that the increases in cocaine self-administration during adulthood following chronic adolescent exposure to $\mathrm{MPH}$ are unlikely to be founded on changes in the aversive properties to cocaine, as evaluated by CTA, but rather could only be related to the alterations in the reinforcing properties of cocaine promoted by previous $\mathrm{MPH}$ exposure. It is relevant to observe that since the neural mechanisms that mediate CTA $^{39}$ are distinguishable from those that mediate reward, ${ }^{40}$ both constructs can vary independently. ${ }^{41,42}$

The study published by Gill et al. ${ }^{35}$ also failed to detect effects in adulthood following 1 year of MPH treatment in 16 male Rhesus monkeys (approximately 37-54 months old, corresponding to a period between 9 and 13 years of age in humans) ${ }^{43}$ using an extended release formulation of $\mathrm{MPH}$ at doses targeted to be within a clinically relevant range. The first objective of this study was to characterize the changes in dopamine transporter (DAT) and DA receptor function through positron emission tomography scans. Availability of these proteins is regularly associated with vulnerability to abuse of psychostimulants. The second objective was to evaluate subjects' morphometric measures, e.g. weight, crownrump length, abdominal and chest circumference. The reason for conducting morphometric assessments lies in the fact that some reports have argued one side effect of $\mathrm{MPH}$ use during development is growth suppression. ${ }^{44,45}$ Finally, the third objective was to evaluate vulnerability to the reinforcing effects of cocaine after pre-exposure to $\mathrm{MPH}$, using the self-administration paradigm. Overall, no differences were found between groups in the availability of D2/D3 or DATs following exposure to MPH during late infancy. There were also no differences in morphometric measurements among animals that had been preexposed to $\mathrm{MPH}$. Additionally, no alterations were observed in the reinforcing properties of cocaine after chronic administration of $\mathrm{MPH}$. Taken together, these results cover three important aspects regarding the use of MPH during infancy and adolescence: body growth, development of the dopaminergic system and future vulnerability to drug abuse. As a result, the authors concluded that their observations support the hypothesis that use of MPH for treatment of ADHD during childhood does not lead to long-term adverse developmental or to neurobiological or behavioral consequences over the course of treatment or later in adolescence.

Several methodological features of this study should be highlighted. The use of non-human primates is advantageous since it presents a higher similarity, in comparison to humans, in terms of neurophysiological processes, developmental windows (infancy and adolescence) and the hormonal and maturational changes and complexity of social and cognitive processes that accompany these periods. Also, the choice of the extended release formulation of $\mathrm{MPH}$ has an important translational aspect, since this kind of formulation prolongs MPH release, maintaining plasma concentrations for a longer period, and is therefore more clinically relevant. ${ }^{46}$ Furthermore, the authors suggest that the non-involvement of MPH in body growth corroborates recent findings demonstrating that while some alterations in measurements such as weight and height may be observed, these effects tend to be attenuated over time and do not impact adult life. ${ }^{47,48}$ Finally, there seems to be an inconsistency among preclinical studies showing no differences in rates of acquisition of cocaine reinforcement after chronic treatment with $\mathrm{MPH} .^{21,22}$ Gill et al. ${ }^{35}$ explain this inconsistency by highlighting the differences in the dose of cocaine initially delivered to the animals in the self-administration paradigm. In this study, Gill et al. ${ }^{35}$ provided the animals with lower initial doses of cocaine, which were below reinforcing thresholds. It therefore seems logical that higher initial doses would result in a more pronounced difference between groups.

\section{Studies reporting effects of early exposure to MPH on adult life}

In contrast to the two studies described above, two other studies did find effects in adulthood following exposure to $\mathrm{MPH}$ during infancy/adolescence. ${ }^{3,21}$ Both works utilized cocaine self-administration after treatment with MPH and compared males of three rodent strains, namely Wistar (WIS), Wistar Kyoto (WKY) and the spontaneously hypertensive rat (SHR), the last of which is widely used as an animal genetic model for ADHD because it exhibits behavioral correlates with this disorder. 49,50 However, each study has some relevant peculiarities. For instance, Harvey et al. ${ }^{21}$ assessed DAT 
functionality in specific brain areas (the prefrontal cortex and striatum), while Jordan et al. ${ }^{3}$ also administered atomoxetine, with the intention of comparing the effects of exposure to both drugs during adolescence on cocaine self-administration during adulthood. Both studies used the same dose of MPH $(1.5 \mathrm{mg} / \mathrm{kg})$ and the same route of administration (oral), finding an increase in the reinforcing properties of cocaine within the SHR group. These results suggest that this model exhibits different effects of adolescent ADHD medications on cocaine intake during adulthood, since it seems to have a greater motivation for cocaine reinforcement after adolescent methylphenidate treatment than do WKY or WIS rats. The mechanisms underlying this potential greater motivation remain elusive. Although the study carried out by Harvey et al., ${ }^{17}$ showed effects on the SHR strain caused by administration of $\mathrm{MPH}$, no significant difference was observed in the functionality of DATs in the areas assessed. The hypothesis that DAT could be involved in this process, since both SHR and ADHD patients have a disturbance in the regulation of DAT translation (Sagvolden et al. ${ }^{51}$ ), was discarded by Harvey et al., ${ }^{21}$ because the results obtained in their study suggest that the enhanced cocaine self-administration in methylphenidate-treated SHRs is not related to potential striatal DAT density changes.

Interestingly, Jordan et al. $^{3}$ did not observe the same effect of exposure to MPH in the SHR strain when atomoxetine was used. The SHR animals treated with $\mathrm{MPH}$ and during adolescence responded differently in terms of cocaine self-administration during adulthood to animals treated with atomoxetine, with $\mathrm{MPH}$ increasing the reinforcing properties of cocaine, whereas atomoxetine did not. These data are in accordance with the results of previous studies using non-human primates. ${ }^{29}$

\section{Studies comparing the effects of different methodological aspects of early exposure to MPH on adult life}

Finally, the three remaining studies organized in this last section share a common feature: they compared methodological aspects. In these studies different strains, behavioral paradigms and $\mathrm{MPH}$ administration protocols are compared.

In the first study, Peña et al. ${ }^{37}$ administered three doses of MPH $(1.25 \mathrm{mg} / \mathrm{kg}, 5 \mathrm{mg} / \mathrm{kg}, 20 \mathrm{mg} / \mathrm{kg}$, ip) and two doses of MET $(1.25 \mathrm{mg} / \mathrm{kg}, 5 \mathrm{mg} / \mathrm{kg}$, ip) to rodents of two different strains (WIS and SHR) before evaluating the same drugs in the CPP task. The objectives of this study were to evaluate the impact of exposure to $\mathrm{MPH}$ during adolescence on its own rewarding effects later in adulthood and to compare the effects of early MPH exposure with those of MET, another psychostimulant drug that has a well-known highly addictive potential. One of the hypotheses was that early exposure to MET could increase its own reinforcing properties later in adulthood in both strains, although with a more pronounced effect on the SHR strain. It was also hypothesized that early exposure to $\mathrm{MPH}$ would increase its own reinforcing properties later in adulthood, particularly in the SHR strain, which is regarded as an ADHD model. Furthermore, the authors also intended to compare the strains (WIS and SHR), since most preclinical studies were conducted with non-ADHD animals, questioning whether the responses of non-ADHD animals could also be generalized to a "pathological" state.

The results show that both WIS and SHR rats, when repeatedly treated with MET, exhibited CPP to this drug in adulthood. However, in contrast with what the authors had hypothesized, in the SHR strain early MPH treatment did not produce CPP when the animals were posteriorly exposed to MPH. Interestingly, WIS rats exhibited a greater response to the rewarding effects of MPH than SHR did. The authors suggested that this could indicate that 'normal' individuals are more vulnerable to $\mathrm{MPH}$ abuse or dependence. With regard to the animals from the SHR strain, the authors pointed out that other studies have also reported results that do not confirm the current position in the literature on this matter. For instance, Yang et al., 52,53 designed an experiment in which three different strains (WKY, SD and SHR) were subjected to chronic administration of a moderate dose of MPH ( $2.5 \mathrm{mg} / \mathrm{kg}$, ip, for 6 days). The MPH treatment elicited locomotor sensitization in WKY and SD rats, but not in SHR. However, as locomotor sensitization and CPP do not assess the same elements of the reinforcing properties of drugs, comparisons between behavioral paradigms should be interpreted with caution. Finally, the authors suggest that MPH may have a better safety profile for treatment of ADHD, compared with MET and/ or amphetamine.

Studies employing behavioral paradigms have observed differing results that vary with different tasks. For instance, increases in the rewarding value of cocaine were observed in rodents submitted to cocaine selfadministration, ${ }^{3,21}$ whereas animals (especially from the SHR strain) tested with the CPP task exhibit decreased rewarding effects. ${ }^{37}$

To address this question, Crawford et al. ${ }^{22}$ compared two different behavioral paradigms with the intention of revealing the effects of early exposure to $\mathrm{MPH}$. This study also investigates sex differences using male and female rodents of the SD strain. The animals were exposed to $\mathrm{MPH}(0.2 \mathrm{mg} / \mathrm{kg}$ or $5 \mathrm{mg} / \mathrm{kg}$, ip) during infancy and, after reaching adulthood, were submitted to cocaine self- 
administration ( 0.25 or $0.75 \mathrm{mg} / \mathrm{kg}$, intravenous) and to the CPP paradigm with cocaine $(0.1$ or $20 \mathrm{mg} / \mathrm{kg}$, ip). Effects were only observed among male subjects that had been exposed to MPH and these effects were only observed in relation to cocaine self-administration. Females used in this study did not exhibit effects of exposure to $\mathrm{MPH}$ in any of the tasks. The authors observed that male rats exposed to MPH during infancy were more susceptible to the reinforcing properties of cocaine (accessed through self-administration) but were not sensitive to the cues related to cocaine, as observed through the CPP task.

The results reported by this study seem to suggest that observation of possible different reinforcing properties of cocaine following MPH administration may vary depending on the characteristics of the behavioral paradigm used. Regarding sex differences, it is relevant to observe that few studies include females in their assessments of early exposure to MPH. However, according to this study published by Crawford et al.22 females seem to display different effects following such exposure when compared to male animals in the same period of the development. This difference may also be reflected in the subsequent predisposition to cocaine abuse. It is possible that hormonal particularities might underlie these differences, since estrogen has a neuroprotective role against some neurotoxic agents. ${ }^{54,55}$

Finally, Griggs et al. ${ }^{23}$ also reported divergent results regarding exposure to $\mathrm{MPH}$ during infancy. In their work, male SD rodents were evaluated between the beginning and end of adolescence. The animals were exposed to MPH for a period of four weeks. Two drug administration protocols were used, continuous ( 1.6 or $3.2 \mathrm{mg} / \mathrm{kg} /$ day via osmotic minipump) and intermittent ( 0.8 or $1.6 \mathrm{mg} / \mathrm{kg}$, subcutaneously, twice daily). After drug administration, the rats were submitted to locomotor activity tests and the self-administration protocol. The effects of exposure to MPH were only observed in subjects that received the drug according to the intermittent administration protocol. Animals that received two daily doses of $\mathrm{MPH}$, rather than receiving it continuously, were more sensitive to the reinforcing properties of cocaine. The authors argue that the results convey enough evidence to state that sustained-release formulations are less likely to elicit the risk of subsequent substance abuse. This hypothesis reinforces the results obtained by Gill et al. ${ }^{35}$ in their study with non-human primates.

\section{Discussion}

This review describes the main results observed after exposure of non-human animal models to $\mathrm{MPH}$ during infancy and adolescence, including the impact of this intervention on subsequent use of psychostimulants during adulthood. The review's findings show that the results are divergent, according to the methodological features of each study. Overall, effects of early exposure to $\mathrm{MPH}$ were observed in studies that utilized an ADHD animal model: SHR rats. This is suggested by the idea that their exposure to MPH during infancy and adolescence underlies the different behavior displayed by the SHR animals towards later exposure to psychostimulants. Nevertheless, some methodological aspects ought to be discussed, since a clearer understanding of these results is warranted.

The first feature that should be highlighted is the range of species and strains utilized in the studies reviewed. Three of the seven studies performed experiments using the SD strain and only one of these ${ }^{23}$ used females in addition to males. Three other studies compared SHR, Wistar and Wistar Kyoto strains. 3,21,22 Two of them observed effects from early exposure to MPH in the SHR strain. ${ }^{3,21}$ These results indicate that development of a model that better mimics this disorder is warranted. Although a number of studies compared several different strains, there are still many studies comparing non-ADHD strains, which may not accurately represent the features of the disorder and the true effects of such exposure on individuals who have the disorder.

One of the studies utilized Rhesus monkeys, a species that can provide a wealth of information due to the considerable similarity of its developmental processes to those of humans. This study did not observe effects from early exposure to MPH nor did it detect alterations to the availability of DAT or to dopaminergic D2 and D3 receptors. One explanation for the lack of an observed effect on this species is founded on the same rationale as the explanation related to rodents, i.e. that this animal is not regarded as an ADHD model. Notwithstanding, Wee \& Woolverton ${ }^{29}$ did demonstrate that MPH elicited reinforcing effects in Rhesus monkeys, which was corroborated by results reported by Lile et al., ${ }^{56}$ with the same animal model. Taken together, these results show that interpretation of the effects of $\mathrm{MPH}$ on non-human primates demands caution, taking into account the lack of consensus in the literature and the methodological diversity/limitations of the studies (e.g. low numbers of individuals per group). Still, considering the similarities of this model when compared to humans, as mentioned above, the results obtained by these studies are of great translational relevance.

Furthermore, it is worth noting that the study conducted by Peña et al., ${ }^{37}$ which compared the SHR and Wistar strains, did not find any effect of early exposure to MPH in the ADHD model strain, although the task carried out was not the same as in studies that 
did find positive effects. Unlike the two other studies, which utilized direct drug administration, Peña et al. ${ }^{37}$ used the CPP task, which indirectly assesses sensitivity to use of psychostimulants and consists of a place-drug association. As such, interpretation of these data requires caution, since the task aims to evaluate the associative rather than the directly rewarding aspects of cocaine.

Another important methodological question that is worth exploring is the dose of MPH used in the studies included in this review. In general, they used doses that are similar to those administered in the corresponding developmental period (infancy and adolescence). Some studies also tested higher doses for the purposes of comparison. The use of a clinically relevant dose is crucial to studies' ecological validity, since the aim is not only to assess the impact of recreational drug use, but also to evaluate the standard pharmacological treatment for ADHD. Two studies also used two other doses, one lower and one higher than the clinical standard. ${ }^{22,36}$ These studies reported effects on CPP and self-administration tasks from early exposure to MPH at these doses. The ecological validity of this intervention is, however, debatable, because the doses administered are not commonly used.

Additionally, the different infusion protocols used by Griggs et al. ${ }^{23}$ are worthy of note. In this study, the authors compared the effects of intermittent vs. continuous administration of $\mathrm{MPH}$. They investigated the impact of different pharmacokinetic behaviors, since sustained-release formulations seem to enhance patient compliance and appear to exert a more limited abuse profile, thus being more difficult to divert for abusive use. The results showed that continuous treatment with $\mathrm{MPH}$ during adolescence caused rats to self-administer less cocaine compared with intermittent administration. Their data therefore suggest that the protocol and dose are relevant issues to address.

The route of administration may also have important implications for the pharmacokinetics of MPH that can profoundly influence the behavioral and neurobiological consequences associated with exposure to this class of drugs. ${ }^{38}$ Clinically, MPH is most commonly available and administered in relatively low doses and typically involves oral administration. ${ }^{57}$ Although animal model studies are increasingly mimicking the therapeutic dose used in humans, a large number of studies over recent decades have been conducted using higher doses and intraperitoneal administration, which leads to a peak plasma drug concentration that exceeds that of clinically relevant administration of $\mathrm{MPH}{ }^{38}$

However, all of the studies reviewed took into account at least one therapeutic dose of $\mathrm{MPH}$, and more than half of these studies were designed to mimic the route of administration typically used in clinical settings, with only two considering sustained-release pharmacokinetics and bioavailability of MPH (Griggs et al. ${ }^{23}$ and Yang et al. ${ }^{35}$ ). This, to a certain extent, provides more clinically meaningful results. These data are also relevant with respect to the inference of behavioral effects of $\mathrm{MPH}$, which are highly correlated with its pharmacokinetics. For instance, immediate release formulations have greater subjective effects, if compared with sustainedrelease formulations. ${ }^{14}$ It is noteworthy that, unlike the higher doses, repeated administration of doses that attempt to approximate the clinical pattern of MPH during adolescence and into early adulthood did not lead to the developmental alterations and neurochemical effects typically associated with psychomotor stimulants. ${ }^{38}$

Furthermore, the three behavioral tasks utilized in the studies included in this review also raise questions relating to the results reported. Four of the seven studies employed self-administration, ${ }^{3,21,23,35}$ while one compared the performance of subjects in terms of selfadministration with performance in the CPP task. ${ }^{22}$ Two other studies utilized either CTA or CPP tasks. ${ }^{36,37}$ The results seem to be consistent throughout the different tasks, to the extent that experimental designs using selfadministration in rodents demonstrate effects of early exposure to $\mathrm{MPH}$, while associative tasks, such as CPP and CTA, also seem to show effects of early exposure, but the effects observed were more subtle.

For instance, the self-administration training represents an instrumental form of conditioning in which the animal actively administers the drug, because it establishes the pairing between the lever press and delivery of the outcome. This allows for assessment of the rewarding properties of drugs in a condition of active consumption. In contrast, CPP evaluates the motivational properties of a specific drug. Furthermore, animals' avoidance of the compartment associated with the drug and their preference for staying in the compartment paired with the vehicle suggests aversive rather than reinforcing properties of the drug. ${ }^{58}$ Similar features are observed in the CTA task, which is based on the fact that animals associate specific interoceptive states (triggered by the drug in this case) with a specific taste. Thus, depending on the discriminative properties of the drug, the subject may (or may not) refrain from ingesting the liquid, suggesting an association with the psychoactive effect of the drug. It is also possible to evaluate an avoidance pattern with this task, implying that the drug elicits aversive properties.

Therefore, it is possible to interpret the results of the studies on the basis of the logic underlying the tasks. As previously mentioned, most of the studies that found effects of early exposure to MPH used self-administration protocols, hence, $\mathrm{MPH}$ may enhance the reinforcing properties of other psychostimulant drugs, in particular, 
cocaine. As for the other behavioral tasks utilized, they may not be suitable for revealing the effects of early exposure to clinically relevant doses of MPH within the ADHD strain. This is supported by the study by Peña et al., ${ }^{37}$ which used CPP to compare the effect of early exposure to MPH on two strains (WIS and SHR). The results only revealed effects on the WIS rats and not on the SHR strain. The authors suggested that these results may be linked to the vulnerability of the non-ADHD brain, because the WIS strain was the only strain displaying such effects. Considering these contrasting results, studies with diverse designs are needed to clarify the relationship between early exposure to MPH and performance in different tasks with regard to the strains utilized.

In general, the data compiled from the studies in this review suggest that exposure to MPH during infancy or adolescence may explain proneness to cocaine abuse, particularly in SHR rats, which constitute an animal model for ADHD. However, the diversity of strains used in the studies and the variety of tasks performed suggest a need for caution when evaluating the results. It is noteworthy that only one study assessed females and although ADHD does predominantly affect males, tests with females are nevertheless warranted if a better understanding of this disorder is to be achieved.

Furthermore, only one of the studies used a species other than rats (Rhesus monkeys), and although this species may offer useful information for a potential translational interpretation of the results, it is understood that the experiments dealt with non-ADHD Rhesus monkeys, which once more raises a crucial point, i.e. that more suitable models are needed to provide a better understanding of this pathology. It is, however, well known that ADHD is a difficult to detect disorder, which may increase rates of false positive diagnoses, in turn implying that healthy subjects might be unnecessarily treated during their developmental periods. This possibility increases the relevance of studies using non-ADHD models, which also ought to be taken into account, since they provide further information on the effects of psychostimulants, especially $\mathrm{MPH}$, on the typical developing brain.

Additionally, it is well known that studies with animals allow for neurobiological, neurochemical and morphological evaluation, and studies with rodents seem to exhibit positive results regarding the risk of psychostimulant consumption following treatment with $\mathrm{MPH}$. Nevertheless, it is worth mentioning that a recently published meta-analysis compiling data from 15 studies with a total of 2,565 children found no effect of early treatment with MPH on later abuse of cocaine, marijuana, alcohol or nicotine. ${ }^{16}$ The authors of that study concluded that use of MPH during childhood is not associated with either a decrease or an increase in proneness to later drug abuse. However, that study only assessed children, not adolescents, and this aspect may be relevant because the stage of development during which the subject is exposed to MPH appears to be a determining factor for prognosis of the disorder.

According to Humphreys, Eng \& Lee, ${ }^{16}$ utilization of $\mathrm{MPH}$ during adolescence may sensitize and thus predispose the subject to later use of psychostimulant drugs, because important neural changes take place within the dopaminergic circuitry of the prefrontal cortex during this stage of development. Therefore, pharmacological interventions interacting with these pathways may alter the perception of the reinforcing properties of psychostimulants later in life.

Finally, it is believed that further studies with both animals and humans are warranted to clarify the real impact of the use of psychostimulants, in particular $\mathrm{MPH}$, on the developing brain, especially concerning the consumption of drugs of abuse.

\section{References}

1. Pardey MC, Kumar NN, Goodchild AK, Clemens KJ, Homewood J, Cornish JL. Long-term effects of chronic oral Ritalin administration on cognitive and neural development in adolescent wistar kyoto rats. Brain Sci. 2012;2:375-404.

2. Andersen SL. Stimulants and the developing brain. Trends Pharmacol Sci. 2005;26:237-43.

3. Jordan CJ, Harvey RC, Baskin BB, Dwoskin LP, Kantak KM. Cocaine-seeking behavior in a genetic model of attention-deficit/ hyperactivity disorder following adolescent methylphenidate or atomoxetine treatments. Drug Alcohol Depend. 2014;140:25-32.

4 . Tripp G, Wickens JR. Neurobiology of ADHD. Neuropharmacology. 2009;57:579-89.

5. American Psychiatric Association. Diagnostic and Statistical Manual of Mental Disorders, Fifth Edition (DSM-5). Arlington: American Psychiatric Publishing; 2013.

6. Schubiner $\mathrm{H}$, Downey $\mathrm{KK}$, Arfken $\mathrm{CL}$, Johanson $\mathrm{CE}$, Schuster $\mathrm{CR}$, Lockhart $\mathrm{N}$, et al. Double-blind placebo-controlled trial of methylphenidate in the treatment of adult ADHD patients with comorbid cocaine dependence. Exp Clin Psychopharmacol. 2002; 10:286-94.

7. Contini V, Rovaris DL, Victor MM, Grevet EH, Rohde LA, Bau $\mathrm{CH}$. Pharmacogenetics of response to methylphenidate in adult patients with Attention-Deficit/Hyperactivity Disorder (ADHD): a systematic review. Eur Neuropsychopharmacol. 2013;23:555-60.

8. Niehaus JL, Murali M, Kauer JA. Drugs of abuse and stress impair LTP at inhibitory synapses in the ventral tegmental area. Eur J Neurosci. 2010;32:108-17.

9. Zlebnik NE, Hedges VL, Carroll ME, Meisel RL. Chronic wheel running affects cocaine-induced c-Fos expression in brain reward areas in rats. Behav Brain Res. 2014;261:71-8.

10. Robison AJ, Vialou V, Mazei-Robison M, Feng J, Kourrich S, Collins $M$, et al. Behavioral and structural responses to chronic cocaine require a feedforward loop involving $\triangle$ FosB and calcium/ calmodulin-dependent protein kinase II in the nucleus accumbens shell. J Neurosci. 2013;33:4295-307.

11. Hiranita $\mathrm{T}$, Soto $\mathrm{PL}$, Newman $\mathrm{AH}$, Katz JL. Assessment of reinforcing effects of benztropine analogs and their effects on cocaine self-administration in rats: comparisons with monoamine uptake inhibitors. J Pharmacol Exp Ther. 2009;329:677-86.

12. Czoty PW, Martelle SE, Gould RW, Nader MA. Effects of chronic methylphenidate on cocaine self-administration under a progressive-ratio schedule of reinforcement in rhesus monkeys. J Pharmacol Exp Ther. 2013;345:374-82.

13. Schindler CW, Gilman JP, Panlilio LV, McCann DJ, Goldberg SR. 
Comparison of the effects of methamphetamine, bupropion, and methylphenidate on the self-administration of methamphetamine by rhesus monkeys. Exp Clin Psychopharmacol. 2011;19:1-10.

14. Kollins SH, MacDonald EK, Rush CR. Assessing the abuse potential of methylphenidate in nonhuman and human subjects: a review. Pharmacol Biochem Behav. 2001;68:611-27.

15. Wilens TE, Faraone SV, Biederman J, Gunawardene S. Does stimulant therapy of attention-deficit/hyperactivity disorder beget later substance abuse? A meta-analytic review of the literature. Pediatrics. 2003;111:179-85.

16. Humphreys KL, Eng $T$, Lee SS. Stimulant medication and substance use outcomes: a meta-analysis. JAMA Psychiatry. 2013:70:740-9.

17. Huston JP, Silva MA, Topic B, Müller CP. What's conditioned in conditioned place preference? Trends Pharmacol Sci. 2013;34:162-6.

18. Napier TC, Herrold AA, de Wit H. Using conditioned place preference to identify relapse prevention medications. Neurosci Biobehav Rev. 2013;37:2081-6.

19. Bardo MT, Bevins RA. Conditioned place preference: what does it add to our preclinical understanding of drug reward? Psychopharmacology (Berl). 2000;153:31-43.

20. Grigson PS. Conditioned taste aversions and drugs of abuse: a reinterpretation. Behav Neurosci. 1997;111:129-36.

21. Harvey RC, Sen S, Deaciuc A, Dwoskin LP, Kantak KM. Methylphenidate treatment in adolescent rats with an attention deficit/hyperactivity disorder phenotype: cocaine addiction vulnerability and dopamine transporter function. Neuropsychopharmacology. 2011;36:837-47.

22. Crawford CA, Baella SA, Farley CM, Herbert MS, Horn LR, Campbell $\mathrm{RH}$, et al. Early methylphenidate exposure enhances cocaine self-administration but not cocaine-induced conditioned place preference in young adult rats. Psychopharmacology (Berl). 2011;213:43-52.

23. Griggs R, Weir C, Wayman W, Koeltzow TE. Intermittent methylphenidate during adolescent development produces locomotor hyperactivity and an enhanced response to cocaine compared to continuous treatment in rats. Pharmacol Biochem Behav. 2010;96:166-74.

24. Rose $J E$, Corrigall WA. Nicotine self-administration in animals and humans: similarities and differences. Psychopharmacology (Berl). 1997; 130:28-40

25. Yang PB, Swann AC, Dafny N. Chronic pretreatment with methylphenidate induces cross-sensitization with amphetamine. Life Sci. 2003;73:2899-2911.

26. Robinson TE, Berridge KC. The neural basis of drug craving: an incentive-sensitization theory of addiction. Brain Res Brain Res Rev. 1993; 18:247-91.

27. Nestler EJ. Molecular basis of long-term plasticity underlying addiction. Nat Rev Neurosci. 2001;2:119-28.

28. Brandon $C L$, Marinelli $M$, Baker LK, White FJ. Enhanced reactivity and vulnerability to cocaine following methylphenidate treatment in adolescent rats. Neuropsychopharmacology. 2001;25:651-61.

29. Wee S, Woolverton WL. Evaluation of the reinforcing effects of atomoxetine in monkeys: comparison to methylphenidate and desipramine. Drug Alcohol Depend. 2004;75:271-6.

30. Justo CC, Carneiro-de-Oliveira PE, Delucia R, Aizenstein ML, Planeta CS. Repeated exposure of adolescent rats to oral methylphenidate does not induce behavioral sensitization or cross-sensitization to nicotine. Braz J Med Biol Res. 2010;43:651-6.

31. Spear LP, Brake SC. Periadolescence: age-dependent behavior and psychopharmacological responsivity in rats. Dev Psychobiol. 1983;16:83-109.

32. Sengupta P. The laboratory rat: relating its age with human's. Int J Prev Med. 2013;4:624-30.

33. Spear LP. The adolescent brain and age-related behavioral manifestations. Neurosci Biobehav Rev. 2000;24:417-63.

34. McNamara JA Jr, Riolo ML, Enlow DH. Growth of the maxillary complex in the rhesus monkey (Macaca mulatta). Am J Phys Anthropol. 1976;44:15-26.

35. Gill KE, Pierre PJ, Daunais J, Bennett AJ, Martelle S, Gage HD, et al. Chronic treatment with extended release methylphenidate does not alter dopamine systems or increase vulnerability for cocaine self-administration: a study in nonhuman primates. Neuropsychopharmacology. 2012;37:2555-65.

36. Wetzell B, Riley AL. Adolescent exposure to methylphenidate has no effect on the aversive properties of cocaine in adulthood. Pharmacol Biochem Behav. 2012;101:394-402.

37. Dela Peña I, Lee JC, Lee HL, Woo TS, Lee HC, Sohn AR, et al. Differential behavioral responses of the spontaneously hypertensive rat to methylphenidate and methamphetamine: lack of a rewarding effect of repeated methylphenidate treatment. Neurosci Lett. 2012;514:189-93.

38. Kuczenski R, Segal DS. Exposure of adolescent rats to oral methylphenidate: preferential effects on extracellular norepinephrine and absence of sensitization and cross-sensitization to methamphetamine. J Neurosci. 2002;22:7264-71.

39. Reilly S. Central gustatory system lesions and conditioned taste aversion. In: Reilly S, Schachtman TR, editors. Conditioned taste aversion: behavioral and neural processes. New York: Oxford University Press; 2009. p. 309-27.

40. Koob GF, Volkow ND. Neurocircuitry of addiction. Neuropsychopharmacology. 2010;35:217-38.

41. Verendeev A, Riley AL. Relationship between the rewarding and aversive effects of morphine and amphetamine in individual subjects. Learn Behav. 2011;39:399-408.

42. Riley AL. The paradox of drug taking: the role of the aversive effects of drugs. Physiol Behav. 2011;103:69-78.

43. Knickmeyer RC, Styner M, Short SJ, Lubach GR, Kang C, Hamer $\mathrm{R}$, et al. Maturational trajectories of cortical brain development through the pubertal transition: unique species and sex differences in the monkey revealed through structural magnetic resonance imaging. Cereb Cortex. 2010;20:1053-63.

44. Safer D, Allen R, Barr E. Depression of growth in hyperactive children on stimulant drugs. N Engl J Med. 1972;287:217-20.

45. Zhang $H$, Du $M$, Zhuang $S$. Impact of long-term treatment of methylphenidate on height and weight of school age children with ADHD. Neuropediatrics. 2010;41:55-9.

46. Patrick KS, González MA, Straughn AB, Markowitz JS. New methylphenidate formulations for the treatment of attentiondeficit/hyperactivity disorder. Expert Opin Drug Deliv. 2005;2:121-43.

47. Rapoport JL, Inoff-Germain G. Responses to methylphenidate in Attention-Deficit/Hyperactivity Disorder and normal children: update 2002. J Atten Disord. 2002;6:S57-60.

48. Biederman J, Spencer TJ, Monuteaux MC, Faraone SV. A naturalistic 10-year prospective study of height and weight in children with attention-deficit hyperactivity disorder grown up: sex and treatment effects. J Pediatr. 2010;157:635-40, 640.e1.

49. Sagvolden T, Metzger MA, Schiorbeck HK, Rugland AL, Spinnangr I, Sagvolden G. The spontaneously hypertensive rat (SHR) as an animal model of childhood hyperactivity (ADHD): changed reactivity to reinforcers and to psychomotor stimulants. Behav Neural Biol. 1992;58:103-12.

50. Wells AM, Janes AC, Liu X, Deschepper CF, Kaufman MJ, Kantak KM. Medial temporal lobe functioning and structure in the spontaneously hypertensive rat: comparison with Wistar-Kyoto normotensive and Wistar-Kyoto hypertensive strains. Hippocampus. 2010;20:787-97.

51. Sagvolden T, Russell VA, Aase H, Johansen EB, Farshbaf M. Rodent models of attention-deficit/hyperactivity disorder. Biol Psychiatry. 2005;57:1239-47.

52. Yang PB, Amini B, Swann AC, Dafny N. Strain differences in the behavioral responses of male rats to chronically administered methylphenidate. Brain Res. 2003;971:139-52

53. Yang PB, Cuellar DO 3rd, Swann AC, Dafny N. Age and genetic strain differences in response to chronic methylphenidate administration. Behav Brain Res. 2011;218:206-17.

54. Arnold S, Beyer C. Neuroprotection by estrogen in the brain: the mitochondrial compartment as presumed therapeutic target. J Neurochem. 2009;110:1-11.

55. Brann DW, Dhandapani K, Wakade C, Mahesh VB, Khan MM. Neurotrophic and neuroprotective actions of estrogen: basic mechanisms and clinical implications. Steroids. 2007;72:381-405.

56. Lile JA, Wang Z, Woolverton WL, France JE, Gregg TC, Davies $\mathrm{HM}$, et al. The reinforcing efficacy of psychostimulants in rhesus monkeys: the role of pharmacokinetics and pharmacodynamics. J Pharmacol Exp Ther. 2003;307:356-66.

57. Wargin W, Patrick K, Kilts C, Gualtieri CT, Ellington K, Mueller RA, et al. Pharmacokinetics of methylphenidate in man, rat and monkey. J Pharmacol Exp Ther. 1983;226:382-6.

58. Laviolette SR, van der Kooy $D$. The neurobiology of nicotine addiction: bridging the gap from molecules to behaviour. Nat Rev Neurosci. 2004;5:55-65.

\section{Correspondence:}

Daniela Martí Barros

Av. Itália, Km 8, Campus Carreiros

96203-900 - Rio Grande, RS - Brazi

E-mail: barrosdm@yahoo.com.br 